\title{
Comportamento dos custos nas empresas listadas na BM\&F Bovespa do segmento de carnes e derivados nos anos de 2004 a 2013
}

Israel Franklin Urzedo Silva Bacharelado em Ciências Contábeis pela Universidade Federal de Uberlândia - UFU Avenida dos Ferreiras, 475, Casa 549. Jd. Califórnia. Uberlândia/MG E-mail: israel@obdc.com.br

Edvalda Araújo Leal Doutorado em Administração pela Fundação Getúlio Vargas - FGV

Professora da Universidade Federal de Uberlândia - UFU Avenida João Naves de Ávila S/N. Santa Mônica. Sala 1F253 E-mail: edvalda@facic.ufu.br

João Antônio de Souza Trindade Bacharelado em Ciências Contábeis pela Universidade Federal de Uberlândia - UFU Rua Chipre, 557. Canaã. Uberlândia/MG E-mail: jdetrindade@gmail.com

\section{RESUMO}

O objetivo geral deste estudo foi verificar como se comportam os custos nas empresas listadas na BM\&F Bovespa, no segmento de carnes e derivados, entre 2004 a 2013. A pesquisa classifica-se como descritiva, com abordagem quantitativa e os procedimentos foram por meio da pesquisa documental, tendo sido utilizadas informações dos demonstrativos contábeis das empresas do segmento de carnes e derivados listadas na BM\&F Bovespa, do período de 2004 a 2013. Para a coleta de dados das empresas participantes do estudo, utilizou-se a base de dados Economática. Os resultados alcançados indicaram que, na análise do segmento de carnes e derivados, $76 \%$ da Receita Líquida de Venda (RLV) destinam-se a cobrir o Custo do Produto Vendido (CPV) no período de 10 anos analisados. Tal percentual é convergente com os resultados encontrados por outros estudos que avaliaram empresas dos diversos setores da economia. Na análise da correlação, confirmou-se que existe forte correlação entre o CPV e RLV, o que demonstra que, no segmento, a alteração RLV tem associação significativa no aumento do CPV, o que poderá influenciar no desempenho das empresas.

Palavras-chave: Comportamento de Custos. Carnes e Derivados. Demonstrativos Contábeis. 
Aplicação do custeio baseado em atividades em uma empresa de serviços rodoviários Edson Roberto Macohon, Jorge Eduardo Scarpin, Wilson Gerigk, Fernanda Castagnolli Domingues, Elvis

Fabio Roman

\section{ABSTRACT}

The aim of this study was to investigate how they behave costs in companies listed on the BM \&F Bovespa in meat and meat products segment between 2004-2013. Research is classified as descriptive and quantitative approach, procedures were through documentary research, information from the financial statements of companies in the meat, and meat products segment listed on the BM\&F Bovespa, the period 2004-2013 were used. To collect data of the participating companies in the study used the data base Economática. The results obtained indicated that the analysis of meat and meat products segment, $76 \%$ of Net Sales Revenue (NSR) are intended to cover the Cost of Goods Sold (COGS) during the 10 years examined this percentage is convergent with results found by other studies evaluating companies from various sectors of the economy. In correlation analysis confirmed that there is strong correlation between the COGS and NSR, which shows that the change in segment NSR has significant influence on the increase in COGS, which may influence the performance of companies.

Keywords: Cost behavior. Meat and Byproducts. Financial statements.

\section{INTRODUÇÃO}

O segmento de carnes e derivados vem se desenvolvendo e aumentando sua escala de produção. De acordo com o Instituto Brasileiro de Geografia e Estatística (IBGE), a produção de bovinos alcançou, em 2013, pelo segundo ano consecutivo, o recorde histórico, com a marca de 34,412 milhões de cabeças abatidas. A produção de Suínos e Frangos também atingiu patamar recorde de produção no ano de 2013 (IBGE, 2013). De acordo com Sehnem et. al. (2012), a internacionalização das empresas do segmento impactou no aumento da produtividade. Além disso, o mercado interno também passou a absorver o aumento da produção (IBGE, 2013).

As mudanças no segmento de carnes e derivados, principalmente, nos países como os Estados Unidos da América, contribuem para as expectativas de que a produção e as exportações aumentem ainda mais. De acordo com a Associação Brasileira das Indústrias Exportadoras de Carne (ABIEC), até o final de 2014, a abertura do mercado dos Estados Unidos para a carne bovina brasileira in natura deve ocorrer, aumentando as perspectivas de novos mercados para o segmento. Em virtude da expansão da produtividade no segmento de carnes e derivados, no mercado interno e 
Aplicação do custeio baseado em atividades em uma empresa de serviços rodoviários Edson Roberto Macohon, Jorge Eduardo Scarpin, Wilson Gerigk, Fernanda Castagnolli Domingues, Elvis

Fabio Roman

externo, e também em função do aumento do nível competitivo, infere-se que as organizações envolvidas nesse setor poderão avaliar seu desempenho financeiro, o que envolve a gestão dos resultados (ABIEC, 2014).

Nesse contexto, o problema de pesquisa que instigou o presente estudo é: Como se comportam os custos em relação as receitas de vendas nas empresas listadas na BM\&F Bovespa, no segmento de carnes e derivados, entre 2004 a 2013? Assim, o objetivo geral da pesquisa é verificar como se comportam os custos em relação as receitas de vendas nas empresas listadas na BM\&F Bovespa, no segmento de carnes e derivados, entre 2004 a 2013.

O presente estudo foi motivado pela pesquisa realizada por Richartz e Borgert (2012), que verificaram como se comportam os custos das empresas brasileiras listadas na BM\&FBOVESPA entre 1994 e 2011, ou seja, os autores abrangeram mais de um setor da economia e sugeriram, para pesquisas futuras, a realização de uma análise detalhada de determinado segmento. Nesse sentido, a realização deste estudo se justifica pela relevância em analisar o comportamento dos custos em um único segmento.

Espera-se que o estudo possa contribuir na evidenciação de informações que abrangem os custos empresariais no setor estudado, auxiliando pesquisadores, gestores e demais interessados às atividades de negócios nesse setor. Segundo Medeiros, Costa e Silva (2005), muitas decisões são sustentadas pelo conhecimento da variação dos custos em função do nível de atividade, proporcionando melhores condições de prever a trajetória organizacional em diversas situações operacionais.

Este trabalho se divide em cinco seções. Além desta introdução, apresenta-se, na segunda seção, a revisão da literatura. Na sequência, na terceira seção, evidenciam-se os procedimentos metodológicos adotados no estudo. Na quarta seção, são apresentados os resultados alcançados na pesquisa. Por último, na quinta seção, encontram-se as considerações finais obtidas com a análise dos resultados, bem como sugestões para futuros estudos. 
Aplicação do custeio baseado em atividades em uma empresa de serviços rodoviários Edson Roberto Macohon, Jorge Eduardo Scarpin, Wilson Gerigk, Fernanda Castagnolli Domingues, Elvis

Fabio Roman

\section{REVISÃO DE LITERATURA}

A revisão de literatura subdivide-se em dois tópicos: primeiramente, apresenta-se a caracterização do segmento de carnes e derivados no Brasil e, posteriormente, aborda-se o comportamento de custos baseado nos estudos similares encontrados na literatura sobre o tema.

\subsection{Caracterização do Segmento de Carnes e Derivados}

Segundo a Associação Brasileira das Indústrias Exportadoras de Carnes (ABIEC), a década de 2000 marcou a consolidação do Brasil como potência na produção e exportação de carne bovina, assumindo o país, em 2004, a primeira colocação no ranking dos exportadores. Em 2011, o Brasil atingiu a marca histórica de produção de carne de frango, totalizando 13,058 milhões de toneladas, conforme dados divulgados pela União Brasileira de Avicultura (UBABEF). Ainda de acordo com a UBABEF, com essa marca histórica, o Brasil está entre os maiores produtores de carne de frango no mundo, ao lado dos Estados Unidos e China.

As projeções do Agronegócio no Brasil de 2012/13 a 2022/23, realizadas pelo MAPA (2014), indicam que o setor de carnes no Brasil deve apresentar intenso crescimento nos próximos anos. Entre as carnes, a que projeta maiores taxas de crescimento da produção no período de 2013 a 2023 é a de frango, que deve crescer anualmente a 3,9\%. Quanto à carne bovina, prevê-se um crescimento projetado nesse período de $2 \%$ ao ano. Essas taxas correspondem a acréscimos na produção da carne de frango de 46,4\% no período de 2013 a 2023, de $22,5 \%$, da carne bovina e de $20,6 \%$, da carne suína. A Figura 1 apresenta a projeção de consumo de carne para o período de 2013 a 2023. 
Aplicação do custeio baseado em atividades em uma empresa de serviços rodoviários Edson Roberto Macohon, Jorge Eduardo Scarpin, Wilson Gerigk, Fernanda Castagnolli Domingues, Elvis

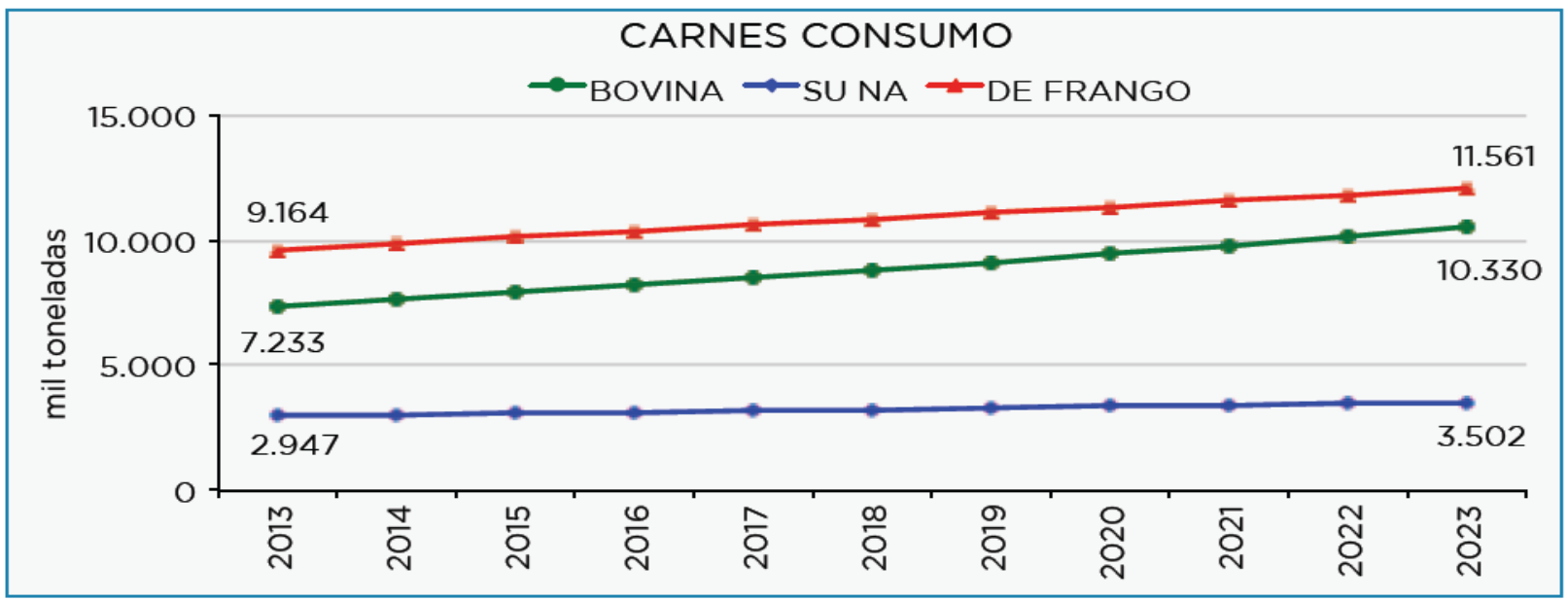

Figura 1 - Projeção Consumo de Carne período 2013 a 2023

Fonte: AGE/MAPA e SGE/Embrapa (2013)

Em relação às exportações de carnes, o Brasil tem abastecido vários países. Em 2012, a carne de frango foi destinada a 152 países, sendo a Arábia Saudita o principal comprador. A Carne bovina foi destinada a 142 mercados, sendo o principal a Rússia, e a carne suína teve 75 países de destino, tendo como principal a Rússia. A expectativa é que esses mercados se consolidem de forma crescente para que sejam factíveis as projeções realizadas (MAPA, 2014).

As informações apresentadas confirmam os dados da pesquisa realizada por Sehnem et. al (2012, p. 17), os quais apontam que as empresas do segmento de carnes e derivados "cresceram e se internacionalizaram nos últimos anos, aumentando o patrimônio, a estrutura produtiva e os rendimentos". Os autores abordam, no estudo realizado, que a capacidade de produção em escala torna essas empresas líderes do segmento.

Considerando o objetivo proposto para este estudo, na sequência, apresentamse os estudos que abordaram a temática de gestão de custos, analisando-se o comportamento dos custos em diversos segmentos. 
Aplicação do custeio baseado em atividades em uma empresa de serviços rodoviários Edson Roberto Macohon, Jorge Eduardo Scarpin, Wilson Gerigk, Fernanda Castagnolli Domingues, Elvis

Fabio Roman

\subsection{Comportamento de Custos}

A gestão estratégica de custos tem extrema importância no processo de tomada de decisão. Sua principal finalidade é fornecer aos administradores informações úteis às decisões, envolvendo o quanto, quando e em que setor deverá ser investido ou sobre quanto devem custar os produtos/serviços que a organização produz (MARTINS, 2009). De acordo com Carpes e Sott $(2007$, p. 6):

A gestão de custos tem por premissa uma sólida composição a respeito de informações dos custos de produção. Toda organização, independentemente do segmento, tem na apuração de seus custos um importante e indispensável instrumento de gestão. A estrutura de custos é formada por sistemas, métodos e formas de custeio.

Nesse sentido, é relevante analisar o comportamento dos custos, o qual é, segundo a definição de Hansen e Mowen (2003, p. 87), "o termo geral para descrever se um custo muda quando o nível de produção muda". Para complementar, Richartz e Borgert (2012) definem comportamento de custos como a forma em que os custos se alteram em função de variações nos níveis de atividades, volume de vendas e estrutura operacional das empresas, considerando as influências ambientais, sociais e econômicas no ambiente competitivo em que as organizações estão inseridas.

O estudo de Luther e Donovan (1998) abordou que em conjunto com o aumento da competitividade, as novas tecnologias proporcionam alterações na estrutura operacional das empresas no ambiente contemporâneo que, por consequência, geram mudanças no comportamento dos custos, tendo em vista que estas alterações acarretam em um aumento na proporção dos custos fixos em relação aos custos totais.

O estudo de Richartz e Borget (2012) analisou as hipóteses de assimetria nos custos com relação à receita total nas empresas brasileiras listadas na BM\&FBOVESPA entre 1994 e 2011. Os resultados indicaram a existência de assimetria nos custos. Segundo os autores, em uma análise subjetiva, existe uma dificuldade em cortar gastos fixos, o que pode comprometer a empresa em períodos de baixa demanda e justificar um dos motivos da assimetria. Além disso, os autores abordam que os custos de mão 
Aplicação do custeio baseado em atividades em uma empresa de serviços rodoviários Edson Roberto Macohon, Jorge Eduardo Scarpin, Wilson Gerigk, Fernanda Castagnolli Domingues, Elvis

Fabio Roman

de obra no Brasil sofrem influências dos sindicatos e leis trabalhistas, gerando pouca flexibilidade para os gestores quanto à redução destes custos. Os resultados do estudo de Subramaniam e Weidenmier (2003) corroboram com os achados de Richartz e Borget (2012) que evidenciam que o nível de variação da receita interfere no comportamento dos custos.

$\mathrm{Na}$ análise de um segmento específico, Kremer, Richartz e Pinheiro (2013) avaliaram o comportamento dos custos das empresas brasileiras do segmento de fios e tecidos listadas na BM\&FBOVESPA no período de 1997 e 2012. O estudo apontou dificuldades encontradas pelas empresas brasileiras do setor na competição com o mercado externo. Assim, o estudo analisou o comportamento dos custos em relação aos valores de importação do setor têxtil. Os resultados indicaram que o comportamento custo do produto vendido (CPV) / Receita Líquida de Venda (RLV) e despesas de vendas (DV)/Receitas Líquidas de Venda (RLV) é maior em momentos em que a importação está em alta. Os autores ressaltam que foi encontrada uma forte correlação entre o CPV/RLV e DV/RLV e os valores de importação.

No setor de telecomunicação, Ferrari, Kremer e Pinheiro (2013) avaliaram o comportamento dos custos ocorridos em função das mudanças regulatórias nas empresas listadas BM\&FBovespa pertencentes ao segmento de Telefonia Fixa e Telefonia Móvel, no período entre 1995 e 2012. Os autores evidenciaram a tendência no aumento dos custos quando ocorrem mudanças nas regulamentações do setor. Tais mudanças aconteceram, principalmente, na década de 90, com a criação da ANATEL e a privatização do setor.

O estudo realizado por Pastre, Borgert e Souza (2013) analisou o comportamento dos custos em relação aos índices de endividamento. A amostra se constituiu de empresas do setor de tecnologia da informação, subsetor de computadores e equipamentos, listadas na BM\&FBovespa, e o período analisado foi de $12 / 2008$ a $03 / 2013$. Os resultados evidenciaram que as variáveis testadas para cada empresa apresentam indicadores de endividamento diferenciados, ou seja, a média do setor não apresentou informações passíveis de generalização para o comportamento dos itens de custos como um todo. 
Aplicação do custeio baseado em atividades em uma empresa de serviços rodoviários Edson Roberto Macohon, Jorge Eduardo Scarpin, Wilson Gerigk, Fernanda Castagnolli Domingues, Elvis

Fabio Roman

Na pesquisa de Zaro e Zaro (2013), os autores avaliaram o impacto da adoção da certificação ISO 14001 nos custos das empresas do setor petroquímico listadas na BM\&FBOVESPA no período de 1994 a 2012. Os achados do estudo indicaram que, no Brasil, o comportamento dos custos é assimétrico, ou seja, nas empresas do setor de petroquímica, o CPV aumenta mais do que as Receitas.

Percebe-se com os resultados evidenciados nos estudos apresentados que 0 comportamento dos custos já foi analisado em vários segmentos, indicando a importância da temática para pesquisas que possam contribuir para prever a trajetória das organizações em diversas situações operacionais (MEDEIROS; COSTA; SILVA, 2005). Para este estudo, escolheu-se o segmento de carnes e derivados.

\section{PROCEDIMENTOS METODOLÓGICOS}

A presente pesquisa classifica-se quanto aos seus objetivos como descritiva, pois visa a demonstrar as características de comportamento do custo das empresas do setor de carnes e derivados listadas na BM\&FBOVESPA, visto que se pretende descrever, relatar e interpretar a realidade observada (BEUREN, 2008).

A abordagem adotada para a pesquisa é predominantemente quantitativa. Segundo Richardson (1999, p.54), esse tipo de abordagem "envolve coletar e analisar dados numéricos e aplicar testes estatísticos, tanto na coleta quanto no tratamento dos dados".

Quanto aos procedimentos técnicos, utilizou-se uma pesquisa de levantamento de dados documental. Para esse levantamento, utilizou-se de base secundária, tendo sido utilizadas informações dos demonstrativos contábeis das empresas do segmento de carnes e derivados listadas na BM\&F Bovespa, do período de 2004 a 2013. Para a coleta de dados das empresas participantes do estudo, utilizou-se a base de dados Economática.

A escolha pelo setor de carnes e derivados refere-se a uma delimitação do estudo, ou seja, a assimetria dos custos depende do ramo de atividade da empresa (SUBRAMANIAM; WEIDENMIER, 2003). Neste contexto, o comportamento dos custos 
Aplicação do custeio baseado em atividades em uma empresa de serviços rodoviários Edson Roberto Macohon, Jorge Eduardo Scarpin, Wilson Gerigk, Fernanda Castagnolli Domingues, Elvis

sofre interferências dos diversos ramos de atividade, pois cada setor possui seu próprio ambiente operacional, envolvendo tecnologias, mercados de produtos e questões regulatórias (RICHARTZ; BORGET, 2012).

A amostra da pesquisa é composta pelas empresas de capital aberto listadas na BM\&FBOVESPA, em 2012, no segmento de carnes e derivados, sendo elas: JBS, Marfrig, Excelsior, Minerva, Minupar e Brasil Foods. Importante destacar que a empresa Minupar não apresentou demonstrativos em todos os anos pesquisados, sendo assim a mesma excluída da amostra.

Importante destacar as duas maiores empresas nesse segmento: a BRF - Brasil Foods S.A. é detentora de marcas fortes, reconhecidas do grande público e referência em qualidade, como Sadia, Perdigão, Chester, Batavo, Elegê e Qualy no Brasil. De acordo com informações disponibilizadas no site da empresa, a produção de carnes, em 2012, foi de 4.250 mil toneladas, e seu faturamento, superior a 28 bilhões de reais. As informações foram disponibilizadas a partir de 2008. Assim, no que se refere aos anos anteriores, as informações foram coletadas dos demonstrativos da empresa Sadia S.A., tendo em vista que, após a fusão entre Sadia e Perdigão, originou-se a Brasil Foods. No que se refere à empresa Perdigão, não foram localizadas informações anteriores ao ano de 2008 no site da Bovespa.

Quanto ao grupo JBS Friboi, que realizou abertura de capital da Companhia em 2007 na B\&MFBovespa, os gestores publicaram a previsão para o ano 2014 de uma receita de $R \$ 100$ bilhões, sendo sua capacidade produtiva de bovinos de 85 mil cabeças abatidas ao dia.

Definida a amostra, foram coletadas na base de dados Economática as informações referentes a: CPV - Custo do Produto Vendido; RLV - Receita Líquida de Vendas; DA - Despesas Administrativas: e DV - Despesas de Vendas das demonstrações contábeis não consolidadas dessas empresas. Em seguida, para fins de análise e operacionalização da pesquisa, essas informações foram exportadas para planilhas do software MS Excel $\AA$, visto que esse software auxilia em cálculos como, por exemplo: i) tendências de comportamento (aumento, diminuição ou estabilidade) das médias das empresas; e ii) as médias de custos de cada empresa ao longo do 
Aplicação do custeio baseado em atividades em uma empresa de serviços rodoviários Edson Roberto Macohon, Jorge Eduardo Scarpin, Wilson Gerigk, Fernanda Castagnolli Domingues, Elvis

Fabio Roman

tempo. Para a realização do teste estatístico de correlação, utilizou-se o software SPSS.

Importante mencionar que, para minimizar as influências temporais sobre os dados quantitativos coletados, os valores foram devidamente ajustados, para dezembro de 2013, pelo Índice IGP-M.

Ainda, importante também é destacar a limitação do estudo. Apesar da utilização da abordagem quantitativa, não se podem identificar todas as variáveis que influenciam o fenômeno pesquisado, não sendo possível, portanto, generalizar os resultados (RICHARDSON, 1999). Neste artigo, os resultados se referem apenas às empresas do segmento de carnes e derivados.

Para analisar o comportamento dos custos e a associação com a receita líquida de venda, foi utilizado o coeficiente de correlação de Spearman. Nesse sentido realizou-se o teste de normalidade de Kolmogorov-Smirnov nos dados, e os mesmos apontaram anormalidade. Segundo Doane e Seward (2008), o teste correlação possibilita medir a força de associação entre duas variáveis, ou seja, quando uma se altera em relação à outra.

Para analisar os coeficientes de correlação, utilizou-se a proposta apresentada por Malhotra (2001), que indica o quão forte é a associação entre as variáveis analisadas, ou seja, o quanto uma variável pode impactar a outra (Tabela 1).

Tabela 1- Coeficientes de Correlação

\begin{tabular}{|c|c|}
\hline Coeficiente de Correlação & Correlação \\
\hline$r=1$ & Perfeita e Positiva \\
\hline $0,8 \leq r<1$ & Forte e Positiva \\
\hline $0,5 \leq r<0,8$ & Moderada e Positiva \\
\hline $0,1 \leq r<0,5$ & Franca e Positiva \\
\hline $0 \leq r<0,1$ & Ínfima e Positiva \\
\hline 0 & Nula \\
\hline$-0,1<r<0$ & Ínfima e Negativa \\
\hline$-0,5<r \leq-0,1$ & Franca e Negativa \\
\hline$-0,8<r \leq-0,5$ & Foderada e Negativa \\
\hline$-1<r \leq-0,8$ & Perfe e Negativa e Negativa \\
\hline$r=-1$ &
\end{tabular}

Fonte: Malhotra (2001) 
Aplicação do custeio baseado em atividades em uma empresa de serviços rodoviários Edson Roberto Macohon, Jorge Eduardo Scarpin, Wilson Gerigk, Fernanda Castagnolli Domingues, Elvis

Fabio Roman

No próximo tópico, Análise dos Resultados, apresentam-se os resultados alcançados.

\section{ANÁLISE DOS RESULTADOS}

\subsection{Tendências de comportamento dos custos}

A partir das análises dos dados apresentados pelas empresas do segmento de carnes e derivados, foi possível identificar o aumento, diminuição ou estabilidade dos custos (CPV) e receitas (RLV) no período de 10 anos analisados. A primeira análise apresenta a variação percentual das receitas líquidas de venda (RLV) de um ano para 0 outro (Tabela 02).

Tabela 2 - Variações das Receitas no Período de 2004 a 2013

\begin{tabular}{|c|c|c|c|c|c|c|c|c|c|}
\hline & & \multicolumn{7}{|c|}{ Período } \\
\cline { 2 - 10 } Empresas & $\mathbf{2 0 0 5}$ & $\mathbf{2 0 0 6}$ & $\mathbf{2 0 0 7}$ & $\mathbf{2 0 0 8}$ & $\mathbf{2 0 0 9}$ & $\mathbf{2 0 1 0}$ & $\mathbf{2 0 1 1}$ & $\mathbf{2 0 1 2}$ & $\mathbf{2 0 1 3}$ \\
\hline JBS & $9 \%$ & $5 \%$ & $-5 \%$ & $9 \%$ & $8 \%$ & $107 \%$ & $5 \%$ & $16 \%$ & $-14 \%$ \\
\hline Marfrig & $2 \%$ & $42 \%$ & $6 \%$ & $-22 \%$ & $35 \%$ & $35 \%$ & $8 \%$ & $-6 \%$ & $-28 \%$ \\
\hline Excelsior & $-6 \%$ & $-12 \%$ & $17 \%$ & $8 \%$ & $18 \%$ & $-19 \%$ & $26 \%$ & $29 \%$ & $-14 \%$ \\
\hline Minerva & $12 \%$ & $22 \%$ & $16 \%$ & $28 \%$ & $21 \%$ & $16 \%$ & $2 \%$ & $0 \%$ & $-20 \%$ \\
\hline Brasil Foods & $14 \%$ & $-9 \%$ & $13 \%$ & $11 \%$ & $-11 \%$ & $14 \%$ & $8 \%$ & $5 \%$ & $39 \%$ \\
\hline
\end{tabular}

Fonte: Dados da pesquisa

Verifica-se, pelos dados coletados, que a empresa que apresentou maior crescimento no período analisado da RLV foi a JBS S.A., apresentando a empresa, de 2004 a 2013, um crescimento de 173\%. Cabe ressaltar que foi no ano de 2004 que a empresa passou a negociar suas ações na BM\&F Bovespa. Outro destaque é para a Brasil Foods. Conforme informado anteriormente, foram analisados os demonstrativos financeiros da Sadia S.A. até o ano de 2008, e, a partir de 2009, após a fusão da mesma com a Perdigão, foi criada a Brasil Foods. Entretanto, no primeiro ano após a 
Aplicação do custeio baseado em atividades em uma empresa de serviços rodoviários Edson Roberto Macohon, Jorge Eduardo Scarpin, Wilson Gerigk, Fernanda Castagnolli Domingues, Elvis

fusão, em 2009, a RLV diminuiu em 11\%. Apenas em 2013, a empresa conseguiu ter um bom aumento de sua RLV, que alcançou $39 \%$.

Percebe-se que, no ano de 2013, somente a Brasil Foods alcançou um crescimento na RLV. Todas as outras empresas analisadas tiverem redução na RLV acima de $14 \%$, sendo o maior decréscimo o da empresa Marfrig, que reduziu $28 \%$ na RLV. Essa empresa, inclusive, acumulou, nos dois últimos anos (2012 e 2013), o decréscimo na RLV.

A Tabela 3 evidencia as variações percentuais dos Custos dos Produtos Vendidos (CPV) no período analisado.

Tabela 3 - Variações dos Custos no Período de 2004 a 2013

\begin{tabular}{|c|c|c|c|c|c|c|c|c|c|}
\hline & & \multicolumn{7}{|c|}{ Período } \\
\cline { 2 - 10 } Empresas & $\mathbf{2 0 0 5}$ & $\mathbf{2 0 0 6}$ & $\mathbf{2 0 0 7}$ & $\mathbf{2 0 0 8}$ & $\mathbf{2 0 0 9}$ & $\mathbf{2 0 1 0}$ & $\mathbf{2 0 1 1}$ & $\mathbf{2 0 1 2}$ & $\mathbf{2 0 1 3}$ \\
\hline JBS & $8 \%$ & $2 \%$ & $-9 \%$ & $21 \%$ & $7 \%$ & $103 \%$ & $1 \%$ & $11 \%$ & $-13 \%$ \\
\hline Marfrig & $-2 \%$ & $36 \%$ & $1 \%$ & $-27 \%$ & $43 \%$ & $43 \%$ & $4 \%$ & $-10 \%$ & $-23 \%$ \\
\hline Excelsior & $-9 \%$ & $-9 \%$ & $25 \%$ & $9 \%$ & $25 \%$ & $-8 \%$ & $7 \%$ & $32 \%$ & $-18 \%$ \\
\hline Minerva & $15 \%$ & $20 \%$ & $19 \%$ & $32 \%$ & $21 \%$ & $14 \%$ & $6 \%$ & $-6 \%$ & $-22 \%$ \\
\hline Brasil Foods & $20 \%$ & $-7 \%$ & $15 \%$ & $15 \%$ & $-10 \%$ & $11 \%$ & $7 \%$ & $12 \%$ & $26 \%$ \\
\hline
\end{tabular}

Fonte: Dados da pesquisa

Os resultados demonstraram que, em todos os anos em que houve decréscimo na RLV, os custos também reduziram. A única exceção foi a Marfrig. No ano 2005, verificou-se que, no período, apesar de o CPV ter diminuído em 2\%, a RLV foi inversamente positiva. Ainda, percebe-se que as empresas Excelsior e Minerva, apesar de terem registrado baixa na RLV em 2013, conseguiram uma redução do CPV maior que a redução na RLV, ou seja, a Excelsior, em 2013, teve uma redução de $18 \%$ dos custos e a Minerva, de 22\%. Já nas RLV, as reduções foram de $14 \%$ e $20 \%$, respectivamente, nessas empresas.

Conforme evidenciado, no período analisado, houve variações na receita e também nos custos. Assim, buscou-se analisar o comportamento dos custos (CPV) de acordo com a variação da receita (RLV). 
Aplicação do custeio baseado em atividades em uma empresa de serviços rodoviários Edson Roberto Macohon, Jorge Eduardo Scarpin, Wilson Gerigk, Fernanda Castagnolli Domingues, Elvis

Fabio Roman

Segundo Richartz e Borgert (2013, p.10), a queda da parcela da receita destinada a cobrir o custo "corrobora as teorias de aumento da concorrência e disputa de mercado entre as empresas, as quais, para se manterem no mercado necessitam aprimorar os sistemas de gestão e se tornarem mais competitivas". Medeiros, Costa e Silva (2005, p.55) complementam a análise, indicando que:

Uma consequência gerencial da análise é que a assimetria dos custos pode ser verificada e controlada. Os administradores podem avaliar sua exposição aos custos assimétricos ao observarem a sensibilidade dos custos a reduções de volume. Eles podem aumentar a sensibilidade dos custos a variações em volume tomando decisões contratuais que reduzem os custos de ajustamento associados a mudar os níveis de recursos contratados.

Os resultados evidenciados no estudo reforçam a relevância da análise do comportamento dos custos para o processo decisório.

\subsection{Médias de Custos de Empresas do Segmento de Carnes e Derivados}

Para análise complementar, apresentam-se as médias das relações: Custo dos Produtos Vendidos/Receita Líquida de Vendas - CPV/RLV; Despesa de venda/Receita de venda líquida - DV/RLV; e Despesa Administrativa/Receita líquida de venda DA/RLV das cinco empresas pesquisadas ao longo dos anos analisados. Na Tabela 4, apresentam-se os resultados alcançados. 
Aplicação do custeio baseado em atividades em uma empresa de serviços rodoviários Edson Roberto Macohon, Jorge Eduardo Scarpin, Wilson Gerigk, Fernanda Castagnolli Domingues, Elvis

Tabela 4 - Média dos Custos e despesas em relação a RLV

\begin{tabular}{|c|c|c|c|c|}
\hline Ano & № empresas & $\begin{array}{c}\text { Média } \\
\text { CPV/RLV }\end{array}$ & $\begin{array}{c}\text { Média } \\
\text { DV/RLV }\end{array}$ & Média DA/RLV \\
\hline 2004 & 5 & 0,752 & 0,138 & 0,040 \\
\hline 2005 & 5 & 0,750 & 0,142 & 0,039 \\
\hline 2006 & 5 & 0,745 & 0,140 & 0,042 \\
\hline 2007 & 5 & 0,746 & 0,134 & 0,041 \\
\hline 2008 & 5 & 0,764 & 0,125 & 0,041 \\
\hline 2009 & 5 & 0,783 & 0,125 & 0,039 \\
\hline 2010 & 5 & 0,801 & 0,125 & 0,032 \\
\hline 2011 & 5 & 0,770 & 0,114 & 0,028 \\
\hline 2012 & 5 & 0,762 & 0,113 & 0.031 \\
\hline 2013 & 5 & 0,748 & 0,113 & 0,026 \\
\hline GERAL & & $\mathbf{0 , 7 6 2}$ & $\mathbf{0 , 1 2 7}$ & $\mathbf{0 , 0 3 6}$ \\
\hline
\end{tabular}

Fonte: Dados da pesquisa

Verifica-se, conforme apresentado na Tabela 4, que, de forma geral, $76 \%$ da RLV destina-se a cobrir o CPV no período de 10 anos analisados nas empresas do segmento de carnes e derivados. Tais resultados são convergentes com os resultados encontrados por Richartz e Borgert (2013) que avaliaram empresas dos diversos setores da economia e encontraram a média de $71,25 \%$ da RLV destinada a cobrir 0 CPV.

No segmento de fio e tecidos, Kremer, Richartz e Pinheiro (2013) identificaram a média da relação entre o CPV e a RLV de 78\%, indicando que, nesse setor, o CPV consome aproximadamente $80 \%$ da Receita Líquida de Vendas. Esses resultados também são próximos aos encontrados no segmento de carnes e derivados.

Em relação às despesas de venda, verificou-se que em média $12 \%$ da RLV são utilizadas para cobrir as despesas de vendas, e 3\% da RLV são consumidas para as despesas administrativas.

\subsection{Análise da Correlação}

Conforme mencionado anteriormente, para medir a covariação entre duas ou mais variáveis, utilizou-se o teste de correlação de postos de Spearman, o qual não requer a suposição de que a relação entre as variáveis é linear. Segundo Hair Jr. et. al. (2005), os pesquisadores buscam verificar se duas ou mais variáveis estão associadas, 
Aplicação do custeio baseado em atividades em uma empresa de serviços rodoviários Edson Roberto Macohon, Jorge Eduardo Scarpin, Wilson Gerigk, Fernanda Castagnolli Domingues, Elvis

Fabio Roman

ou seja, quando uma se altera em relação à outra, o que pode ser avaliado a partir do coeficiente de correlação.

A Tabela 5 apresenta a correlação das variáveis: Receita Líquida de Venda; Custo do Produto Vendido; Despesa de Venda; e Despesa Administrativa.

Tabela 5 - Correlação de Spearman

\begin{tabular}{|c|c|c|c|c|}
\hline Variáveis & RLV & CPV & DV & DA \\
\hline RLV & 1 & & & \\
\hline CPV &, $998^{*}$ & 1 & & \\
\hline DV &, $952^{*}$ &, $953^{*}$ & 1 & \\
\hline DA &, $940^{*}$ &, $934^{*}$ &, $850^{*}$ & 1 \\
\hline
\end{tabular}

Fonte: Dados da pesquisa

*Significativo ao nível de 0,01\% Legenda:

RLV: Receita Líquida de Venda

CPV: Custo do Produto Vendido

DV: Despesa de Venda

DA: Despesa Administrativa

A partir dos dados evidenciados na Tabela 5, verifica-se que a RLV revelou correlação significativa positiva com o CPV, DV e DA, acima de 90\%, o que indica forte associação entre as variáveis (MALHOTRA, 2001). Esses resultados indicam que, quando altera a RLV, existe uma forte correlação de alteração nas variáveis CPV, DV e DA, ou seja, o custos e despesas tendem a seguir o aumento das receitas na mesma proporção. Verificou-se também uma forte correlação (acima de 90\%) do CPV em relação à DV e à DA, indicando uma associação entre as variáveis.

O estudo realizado por Kremer, Richartz e Pinheiro (2013), no setor de fios e tecidos, também identificaram forte correlação entre o CPV, DV e DA em relação à Receita Líquida de Venda. 
Aplicação do custeio baseado em atividades em uma empresa de serviços rodoviários Edson Roberto Macohon, Jorge Eduardo Scarpin, Wilson Gerigk, Fernanda Castagnolli Domingues, Elvis

Fabio Roman

\section{CONSIDERAÇÕES FINAIS}

Considerando o objetivo geral proposto para este estudo, analisou-se o comportamento dos custos nas empresas listadas na BM\&F Bovespa no segmento de carnes e derivados entre 2004 a 2013. Primeiramente, analisaram-se as tendências de comportamento dos custos quanto às variações das Receitas Líquidas de Vendas e o Custo do Produto Vendido.

De acordo com as análises, verificou-se que as empresas apresentaram crescimento na RLV no acumulado dos 10 anos analisados, comprovando o crescimento do faturamento do setor. Nos 10 anos analisados, observou-se que, em 8 deles, a empresa a JBS conseguiu diminuir seu CPV em relação ao RLV. Identificou-se também que, no ano de 2013, houve maior crescimento da RLV da empresa Brasil Foods, o que ilustra o período de maior crescimento, após a fusão entre Sadia e Perdigão

É importante ressaltar que, na análise do segmento de carnes e derivados, $76 \%$ da RLV destina-se a cobrir o CPV no período de 10 anos analisados. Esse percentual é convergente com os resultados encontrados por Richartz e Borgert (2013) que avaliaram empresas dos diversos setores da economia.

$\mathrm{Na}$ análise da correlação, os resultados confirmaram que existe forte correlação entre o CPV e RLV $(0,998)$, o que demonstra que, no segmento, a alteração RLV tem associação significativa no aumento do CPV, o que poderá afetar o desempenho das empresas. Esse resultado vai de encontro com a tendência das empresas do segmento, que é o investimento voltado para a produtividade e a produção em escala, aumentando o lucro pelo aumento do giro de vendas. Verificou-se, ainda, que as despesas administrativas (DA) e despesas de venda (DV) também apresentaram forte correlação com RLV.

De acordo com Sehnem et. al (2012), percebe-se, também, que as empresas do segmento de carnes e derivados, nos últimos anos, focaram-se no aumento da produção, o que impacta no aumento da RLV, ou seja, evidencia melhorias na eficiência operacional, seja pela redução de custos ou aumento de receitas. Dessa 
Aplicação do custeio baseado em atividades em uma empresa de serviços rodoviários Edson Roberto Macohon, Jorge Eduardo Scarpin, Wilson Gerigk, Fernanda Castagnolli Domingues, Elvis

Fabio Roman

forma, espera-se que os resultados encontrados neste trabalho possam contribuir para a análise informacional do setor para os usuários externos (analistas financeiros, investidores etc.) no processo de avaliação do desempenho econômico-financeiro das empresas, bem como para gestores dessas organizações que poderão avaliar o comportamento dos custos nas atividades dos negócios.

É relevante evidenciar a limitação do estudo, por analisar somente um segmento, os resultados não podem ser generalizados para outros setores. Para futuras pesquisas, sugere-se analisar outros segmentos para possibilitar comparações com os resultados alcançados neste estudo. Além disso, sugere-se analisar fatores determinantes que podem afetar o comportamento dos custos, como: ambientes regulatórios; grau de tecnologia associada ao setor; capacidade ociosa nas organizações; efeitos de períodos anteriores, dentre outros.

\section{REFERÊNCIAS}

ABIEC Associação Brasileira das Indústrias Exportadoras de Carne. Pecuária Brasileira. Disponível em:<http://www.abiec.com.br/3_pecuaria.asp>. Acesso em: 02/fev/2014.

BEUREN, I. M. (Org.) e outros. (2008). Como elaborar trabalhos monográficos em Contabilidade. São Paulo: Atlas.

CARPES, A. M.; SOTT, V. R. Um estudo exploratório sobre a sistemática de gestão de custos das agroindústrias familiares, estabelecidas no extremo oeste do Estado de Santa Catarina-Brasil. Disponível em: <http://www.custoseagronegocioonline.com.br/numero1v3/agronegocio\%20familiar.pdf> Acesso em: 20/fev/2014.

DOANE D. P.; SEWARD L. E. (2008). Estatística aplicada à administração e à Economia. São Paulo: McGraw-Hill.

FERRARI, M. J.; KREMER, A.W.; PINHEIRO, N. S. (2013). Análise do comportamento dos custos no setor de telecomunicações. In: XIX Congresso Brasileiro de Custos. Uberlândia-MG. Anais...Uberlândia, 1 CD ROM.

HAIR JR., J. F.; BABIN, B.; MONEY, A. H.; SAMOUEL, P. (2005). Fundamentos de métodos de pesquisa em Administração. Porto Alegre: Bookman. 
Aplicação do custeio baseado em atividades em uma empresa de serviços rodoviários Edson Roberto Macohon, Jorge Eduardo Scarpin, Wilson Gerigk, Fernanda Castagnolli Domingues, Elvis

Fabio Roman

HANSEN, Don R.; MOWEN, Maryanne M. (2003). Gestão de custos: contabilidade e controle. São Paulo: Pioneira Thomson Learning.

IBGE - Instituto Brasileiro de Geografia e Estatística. Indicadores IBGE 2013. Disponível

em: <http://www.ibge.gov.br/home/estatistica/indicadores/agropecuaria/producaoagropecuar ia/abate-leite-couro-ovos_201304comentarios.pdf>. Acesso em: 19/jun/2014

KREMER, A. W.; RICHARTZ, F.; PINHEIRO, N. S. (2013). O impacto das importações no comportamento dos custos das empresas do segmento de fios e tecidos da BM\&FBovespa. In: XIX Congresso Brasileiro de Custos. Uberlândia-MG. Anais...Uberlândia. 1 CD ROM.

LUTHER, R.; DONOVAN, B. O'. (1998). Cost-volume-profit analysis and the theory of constraints. Journal of Cost Management. p.16-21. Setembro/Outubro.

MALHOTRA, K. N. (2001). Pesquisa de Marketing. Porto Alegre: Bookman.

MAPA Ministério da Agricultura e Pecuária Brasileira. Projeções do Agronegócio Brasil 2012/13 a 2022/23 - projeções de longo prazo. Disponível em: <http://www.agricultura.gov.br/arq_editor/projecoes\%20-\%20versao\%20atualizada.pdf>. Acesso em: 10/fev/2014.

MARTINS, E. (2009). Contabilidade de Custos. (9 ed.). São Paulo: Atlas.

MEDEIROS, Otávio R.; COSTA, Patrícia S.; SILVA, César A. T. (2005). Testes Empíricos Sobre o Comportamento Assimétrico dos Custos nas Empresas Brasileiras. Revista de Contabilidade e Finanças - USP. São Paulo, n. 38, p. 47 - 56, Maio/Ago.

PASTRE, F.; BORGERT, A.; SOUZA, F.R. (2013). Comportamento dos custos e indicadores de endividamento do setor de tecnologia da informação da BM\&FBovespa. In: XIX Congresso Brasileiro de Custos. Uberlândia-MG. Anais... Uberlândia. 1 CD ROM.

RICHARDSON, Robert Jarry. (1999). Pesquisa social: métodos e técnicas. São Paulo: Atlas.

RICHARTZ, Fenando; et. al. (2012). Comportamento dos custos das empresas brasileiras listadas no segmento de Fios e Tecidos da BM\&FBOVESPA entre 1998 e 2010. XIX Congresso Brasileiro de Custos. Bento Gonçalves, RS, Brasil.

RICHARTZ, Fernando; BORGERT, Altair. (2012). O comportamento dos custos das empresas brasileiras listadas na BM\&F Bovespa entre 1994 e 2011. Disponível em: <http://www.furb.br/_upl/files/especiais/anpcont\%207/3806/ccg\%2040.pdf?2013090302 5300 >. Acesso em: 09/set/2013. 
Aplicação do custeio baseado em atividades em uma empresa de serviços rodoviários Edson Roberto Macohon, Jorge Eduardo Scarpin, Wilson Gerigk, Fernanda Castagnolli Domingues, Elvis

Fabio Roman

SEHNEM, S.; FISCHER, A.; ALBERTON, A.; AGNOL, R. M. D. Análise do desempenho de empresas do segmento de carnes e derivados listadas na BM\&FBovespa. Disponível em: <http://periodicos.ufpel.edu.br/ojs2/index.php/AT/article/viewFile/743/947> Acesso em: 15/out/2013.

SUBRAMANIAM, Chandra; WEIDENMIER, Marcia L. (2003). Additional evidence on the sticky behavior of costs. Social Science Research Network. Disponível em: <http://ssrn.com/abstract=369941 >. Acesso em: 25/jun/2012.

UBABEF - União Brasileira de Avicultura. A Avicultura Brasileira. Disponível em: <http://www.ubabef.com.br/a_avicultura_brasileira/historia_da_avicultura_no_brasil>. Acesso em 02/fev/2014.

ZARO, E. S.; ZARO, C. Z. (2013). O reflexo da implantação da ISO 14001 no comportamento dos custos das empresas do setor petroquímico da BM\&FBOVESPA. In: XIX Congresso Brasileiro de Custos. Uberlândia-MG. Anais...Uberlândia.1 CD ROM.

Data de Submissão: 23/01/2015 Data de Aceite: 01/10/2015 